\title{
Slouching towards gene therapy for hypercholesterolemia
}

\author{
Friedrich C. Luft
}

Published online: 10 May 2011

(C) Springer-Verlag 2011

Familial hypercholesterolemia (FH) occurs in about 1 of 800 births in Europe and North America. FH patients are heterozygous for mutations in the low-density lipoprotein receptor (LDLR) and harbor about $50 \%$ of the necessary LDLR on their hepatocytes. FH patients develop atherosclerosis at an early age, but can be helped with statin therapy and LDL apheresis when necessary. Homozygous FH patients are rare (about 1 in 1,000,000 births); a hand full resides in my hometown. However, in other parts of the world, homozygous FH is more common. These patients have no LDLR, and they die of atherosclerosis as children or in young adulthood. Their cholesterol levels are about five-fold above normal values. Clinically, huge xanthomas are common (Fig. 1).

In this issue of Journal of Molecular Medicine, Van Craeveld et al. [1] report on plaque regression following gene transfer strategies in LDL receptor gene-deleted mice (LDLR-/-) fed a high-fat diet. They relied on an adenoviral LDLR (AdLDLR) or apolipoprotein AI (AdA-1) to raise high-density lipoprotein (HDL) levels, or a combination of both gene transfer strategies. A glance at their figure is convincing. The mice had received the diet for 6 months and had total cholesterol values above $700 \mathrm{mg} / \mathrm{dl}$. After AdLDLR transfer, either alone or in the combination, cholesterol values plummeted to $100 \mathrm{mg} / \mathrm{dl}$ or less for the subsequent 12 weeks observation, without repeat treatments. Administering the AdA-1 construct raised HDL values to $>100 \mathrm{mg} / \mathrm{dl}$. Interestingly, the combination was

F. C. Luft $(\square)$

Experimental and Clinical Research Center, Charité Medical, Faculty and Max-Delbrück Center for Molecular Medicine, Berlin, Germany

e-mail: luft@charite.de less effective in raising HDL concentrations. The authors monitored vessel repair. They observed a plaque reduction of almost $30 \%$ by 12 weeks. A human trial of the most effective statin achieved about 6\% [2]. The combinedtreatment approach showed a hint of additive effects. The report drives two points home. The first is that we now have a utilitarian model of plaque regression and repair mechanisms that make other models pale in significance. The second is that the dream of "gene therapy" for homozygous familial hypercholesterolemia could enjoy a "second coming":

The authors seem to have done their homework on adenoviral gene transfer. This double-stranded DNA virus that was first isolated from adenoids $>60$ years ago, has become a workhorse. The DNA replication process separates the adenoviral life cycle into two phases, namely an early and a late phase. In both, a primary transcript that is alternatively spliced to generate monocistronic mRNAs compatible with the host's ribosome is generated. The early (E) genes are responsible for expressing mainly nonstructural, regulatory proteins. These proteins have three functions. They alter the expression of host proteins that are necessary for DNA synthesis. They activate other viral genes such as the virus-encoded DNA polymerase. They avoid premature death of the infected cell by the hostimmune defenses. This function is achieved by the blockage of apoptosis, blockage of interferon activity, and blockage of MHC class I translocation and expression. Crouzet et al. [3] introduced a two-step cloning procedure that allowed the introduction of multiple independent modifications within the adenoviral genome. They demonstrated the recovery of several E1E3E4-deleted adenoviruses following transfection of the corresponding Escherichia coli-derived genomes in a cell line. The De Geest laboratory has worked extensively on E1E3E4- 




Fig. 1 Lipid-laden xanthomas on the knees of a homozygous familial hypercholesterolemia patient with an LDL cholesterol of $567 \mathrm{mg} / \mathrm{dl}$

deleted adenoviral vectors [4]. There experience is evidenced by the success in this report.

In an earlier report [5], the authors tested the effects of gene transfer with the same adenoviral vectors expressing the LDLR or the very LDLR. In that study, they used the same LDLR-/- mice. In that study, they also found that non-HDL lipoproteins were more atherogenic in female mice, independent of sex differences in plasma HDL cholesterol levels. They further observed that AdLDLR did not induce cholesterol accumulation in the liver and that cholesterol content in the myocardium, quadriceps muscle, and kidney were reduced. Their study spanned 6 months. Kassim et al. [6] recently reported similar findings. They also used adeno-associated viral vectors to deliver the gene for mouse LDLR to a double-knockout model missing both the LDLR and the apolipoprotein B. A single intravenous injection of their construct also reduced plasma cholesterol and non-HDL cholesterol levels. Whereas fat-fed control mice experienced a further $65 \%$ progression in atherosclerosis over 2 months, the treated mice exhibited an $87 \%$ regression of atherosclerotic lesions after 3 months compared to baseline mice.

The studies in mice are relatively short term. The mouse life span comprises about 2 years. Survival studies in the mice with detailed hepatic inspection are warranted, not only because of viral-related effects, but also because LDLR overexpression could have consequences. Hibbitt et al. [7] generated vectors in which the LDLR gene or luciferase reporter gene expression was driven by $10 \mathrm{~kb}$ of human LDLR genomic DNA. Their construct encompassed the promoter region including elements essential for physiologically regulated expression. They found that in vitro, the genomic promoter element conferred long-term, physiologically regulated gene expression and complementation of receptor deficiency in culture over 240 cell generations. In vivo, they demonstrated efficient liverspecific delivery and expression of luciferase following tail-vein injection and confirmed that expression from the LDLR promoter element was sensitive to statin administration. They also documented long-term LDLR expression from the $10-\mathrm{kb}$ promoter element up to 9 months following delivery. The vector system that they described provided the efficient delivery, long-term expression, and physiological regulation required for a successful gene therapy, at least for mice.

Adenoviruses and adeno-associated viruses currently appear to be the most efficient vectors for delivering therapeutic genes into the cardiovascular system. Gene transfer using local gene delivery techniques have been shown to be superior to less-targeted intra-arterial or intravenous applications. To date, no virally delivered gene therapy drugs have been approved for clinical use in cardiovascular applications [8]. The reason for reluctance and extreme concerns regarding safety are surely related to the death of a relatively fit 18 -year-old with an inherited enzyme deficiency, who died 4 days after doctors injected a genetically altered virus into his liver [9]. Thus, we are content to slouch rather than run to our hopefully far better second coming.

Respectfully,

Friedrich C. Luft

\section{References}

1. Van Craeyveld E, Gordts SC, Nefyodova E, Jacobs F, De Geesst B (2011) Regression and stabilization of advanced murine atherosclerotic lesions: a comparison of LDL lowering and HDL raising gene transfer strategies. J Mol Med. doi:10.1007/s00109-011-0722-x

2. Nissen SE, Nicholls SJ, Sipahi I, Libby P, Raichlen JS, Ballantyne CM, Davignon J, Erbel R, Fruchart JC, Tardif JC et al (2006) Effect of very high-intensity statin therapy on regression of coronary atherosclerosis: the ASTEROID trail. JAMA 295:1556-1565

3. Crouzet J, Naudin L, Orsini C, Vigne E, Ferrero L, Le Roux A, Benoit P, Latta M, Torrent C, Branellec D, Denèfle P, Mayaux JF, Perricaudet M, Yeh P (1997) Recombinational construction in Escherichia coli of infectious adenoviral genomes. Proc Natl Acad Sci U S A 94:1414-1419

4. Jacobs F, Snoeys J, Feng Y, Van Craeyveld E, Lievens J, Armentano D, Cheng SH, De Geest B (2008) Direct comparison of hepatocyte-specific expression cassettes following adenoviral and nonviral hydrodynamic gene transfer. Gene Ther 15:594-603, Epub 2008 Feb 21

5. Jacobs F, Van Craeyveld E, Feng Y, Snoeys J, De Geest B (2008) Adenoviral low density lipoprotein receptor attenuates progression of atherosclerosis and decreases tissue cholesterol levels in a murine model of familial hypercholesterolemia. Atherosclerosis 201:289-297 
6. Kassim SH, Li H, Vandenberghe LH, Hinderer C, Bell P, Marchadier D, Wilson A, Cromley D, Redon V, Yu H, Wilson JM, Rader DJ (2010) Gene therapy in a humanized mouse model of familial hypercholesterolemia leads to marked regression of atherosclerosis. PLoS ONE 5(10):e13424

7. Hibbitt OC, McNeil E, Lufino MM, Seymour L, Channon K, Wade-Martins R (2010) Long-term physiologically regulated expression of the low-density lipoprotein receptor in vivo using genomic DNA mini-gene constructs. Mol Ther 18 (2):317-326

8. Rissanen TT, Ylä-Herttuala S (2007) Current status of cardiovascular gene therapy. Mol Ther 15(7):1233-1247

9. Marshall E (1999) Gene therapy death prompts review of adenovirus vector. Science 286:2244-2245 